\title{
Hypotension Aggravated by Dopamine in a Dog Under Isoflurane Anesthesia
}

\author{
Elizabeth Regina Carvalho', Natache Arouca Garofaloº ${ }^{2}$ Carolina Hagy Girotto² \& Francisco José Teixeira Neto²
}

\begin{abstract}
Background: Hypotension (MAP $<60 \mathrm{mmHg}$ ) is the most common complication in anesthetic practice and has been identified in $38 \%$ of canine patients undergoing general anesthesia for variety of procedures. Normalization of arterial pressure can usually be achieved by decreases in inhalant anesthetic concentrations, fluid administration, and use of inotropes/ vasopressors in healthy animals (ASA I) or animals with mild systemic disease (ASA anesthetic risk II). The present report shows an ASA II dog with severe hypotensive crisis [mean arterial pressure (MAP) $<50 \mathrm{mmHg}$ ] during general anesthesia, in which the procedure was aborted because hypotension was aggravated by dopamine.

Case: A 7-year-old male Bull Terrier was anesthetized for magnetic resonance imaging (MRI) of a tumor in the face. After intramuscular acepromazine $(0.01 \mathrm{mg} / \mathrm{kg})$ and meperidine $(3 \mathrm{mg} / \mathrm{kg})$, anesthesia was induced with intravenous (IV) ketamine $(1 \mathrm{mg} / \mathrm{kg})$ and propofol $(2.3 \mathrm{mg} / \mathrm{kg})$ and maintained with isoflurane in oxygen. Ten min after induction of anesthesia MAP was $45 \mathrm{mmHg}$, while end-tidal isoflurane $\left(\mathrm{ET}_{\mathrm{ISO}}\right)$ concentration was $0.5 \%$. End-tidal isoflurane was decreased to $0.3 \%$ and an IV bolus of Lactated Ringer's was initiated $(15 \mathrm{~mL} / \mathrm{kg}$ over $10 \mathrm{~min})$, followed by two ephedrine boluses $(0.1$ $\mathrm{mg} / \mathrm{kg}$, IV) administered $5 \mathrm{~min}$ apart. MAP remained low $(<50 \mathrm{mmHg})$ and dopamine constant rate infusion (CRI) was initiated ( $7.5 \mu \mathrm{g} / \mathrm{kg} / \mathrm{min})$. Ten minutes after dopamine CRI was commenced, MAP was further decreased to $25-22 \mathrm{mmHg}$. Dopamine CRI was increased to $10 \mu \mathrm{g} / \mathrm{kg} / \mathrm{min}$, but MAP remained $<25 \mathrm{mmHg}$. Infusion drugs and isoflurane anesthesia were stopped. After the animal was extubated MAP returned 60-70 $\mathrm{mmHg}$.

Discussion: Among the drugs used, isoflurane is known for decreasing blood pressure in a dose-related manner because of its vasodilating properties. Hypotension is rarely associated with low end-tidal isoflurane concentrations $(0.3-0.5 \%)$ in animals that do not present previous evidence of circulatory dysfunction. Acepromazine may have contributed to the hypotensive actions of isoflurane in the case reported here because of its vasodilating effects. Acepromazine has prolonged plasma half-life $(7 \mathrm{~h})$ and might also have contributed to the lack efficacy of ephedrine to treat hypotension. Aggravation of hypotension (MAP decreased from $45-50 \mathrm{mmHg}$ to approximately $25 \mathrm{mmHg}$ ) by dopamine was unexpected. Aggravation of hypotension during administration of vasopressor doses of dopamine could be related to the activation of the cardiopulmonary chemoreflex (CCR), previously known with the eponym Bezold-Jarisch reflex or due to a prevalence of dopamine's vasodilatory effects (dopaminergic receptor stimulation) and failure of this drug in promiting increased CO and SVR at the dose ranges used ( 7.5 to $10 \mu \mathrm{g} / \mathrm{kg} / \mathrm{min}$ ).. The CCR involves activation of mechano and baroreceptors in the heart, by inotropes such as dopamine and dobutamine. This activation originates vagal afferent impulses to the nucleus tractus solitarii of the spinal cord, which in turn originates parasympathetic afferent impulses to the heart. The consequence is an increase in parasympathetic outflow and decreased sympathetic activity, ultimately producing bradycardia, hypotension, or both.
\end{abstract}

Keywords: acepromazine, Bezold-Jarish reflex, cardiopulmonary chemoreflex, canine, inotropes. 


\section{INTRODUCTION}

Hypotension (MAP $<60 \mathrm{mmHg}$ ) is the most common complication in anesthetic practice and has been identified in $38 \%$ of canine patients undergoing general anesthesia for variety of procedures [15]. However, this anesthetic-related complication is usually responsive to standard therapeutic measures which include decreases in inhalant anesthetic concentrations, fluid administration, and use of inotropes/vasopressors in healthy animals (ASA I) or animals with mild systemic disease (ASA anesthetic risk II). The present report shows an ASA II dog with severe hypotensive crisis (MAP $<50 \mathrm{mmHg}$ ) during general anesthesia, in which the procedure was aborted because this complication was aggravated by dopamine.

\section{CASE}

A 7-year-old male Bull Terrier with a previous history of squamous cell carcinoma was admitted at a Veterinary Teaching Hospital because of a nodule near the right third eyelid (Figure 1). This nodule was suspected as squamous cell carcinoma by fine needle aspiration cytology, and evidence of zygomatic arch bone lysis was present on radiographs. Magnetic resonance imaging (MRI) and a computed tomography (CT) were indicated as part of surgical and radiotherapy planning. Two days before MRI and CT, blood samples were taken for $\mathrm{CBC}$ and biochemistry profile. The CBC showed leukopenia $(5.400 / \mu \mathrm{L})$, due to lymphopenia $(300 \mu \mathrm{L})$, and thrombocytopenia $(30.000 \mu \mathrm{L})$. Hematocrit, total plasma protein and albumin values were $36 \%, 7.8 \mathrm{~g} / \mathrm{dL}$, and $2.5 \mathrm{~g} / \mathrm{dL}$ respectively. The biochemistry profile showed that both liver and kidney function markers were within the reference values.

Food was withheld $12 \mathrm{~h}$ before anesthesia. Physical examination performed prior to anesthesia did not show remarkable changes. The dog's behavior was docile but agitated, and acepromazine $(0.01 \mathrm{mg} /$ $\mathrm{kg}$ ) and meperidine $(3 \mathrm{mg} / \mathrm{kg}$ ) were given intramuscularly as premedication. A 20 Gauge catheter was placed in a cephalic vein, and anesthesia was induced with intravenous ketamine $(1 \mathrm{mg} / \mathrm{kg}$ ) followed by propofol titrated until orotracheal intubation was possible $(2.3 \mathrm{mg} / \mathrm{kg})$. Anesthesia was maintained with isoflurane in oxygen under spontaneous ventilation and the vaporizer settings were initially adjusted to $1.5 \%$ during instrumentation (placement of ECG electrodes, esophageal thermometer, pulse oximetry and anesthetic agent/carbon dioxide gas analyzer).

Immediately after orotracheal intubation, a dorsal pedal artery was catheterized with a 22 Gauge catheter and connected via a non-compliant tubing to a pressure transducer. The transducer was connected to the MRI compatible monitor (Medrad Veris 8600 MRI Patient Monitoring Systems) ${ }^{1}$ zeroed at the heart level for monitoring systolic, diastolic, and mean arterial pressures (SAP, DAP, and MAP). Oxygen saturation was recorded by a pulse oxymeter $\left(\mathrm{SpO}_{2}\right)$ with the MRI compatible probe connected to the prepuce; while end-tidal isoflurane concentrations $\left(\mathrm{ET}_{\mathrm{ISO}}\right)$ and carbon dioxide $\left(\mathrm{ETCO}_{2}\right)$ were monitored by an infrared anesthetic agent analyzer.

The MRI compatible ECG leads were attached to the thorax, with the right and left arm electrodes attached near the armpits and the left leg electrode attached as close as possible to the left leg and lead II configuration was selected for monitoring heart rate (HR) and rhythm with a MRI compatible monitor. Throughout anesthesia $\mathrm{HR}$ and $\mathrm{SpO}_{2}$ ranged from 96 to $114 \mathrm{bpm}$ and from 97 to $100 \%$, respectively. Although the respiratory rate remained relatively low (6 to 10 breaths/min), low $\mathrm{ETCO}_{2}$ values (20 to $25 \mathrm{mmHg}$ ) were recorded during anesthesia with a clearly identifiable expiratory plateau (phase III) in the capnogram.

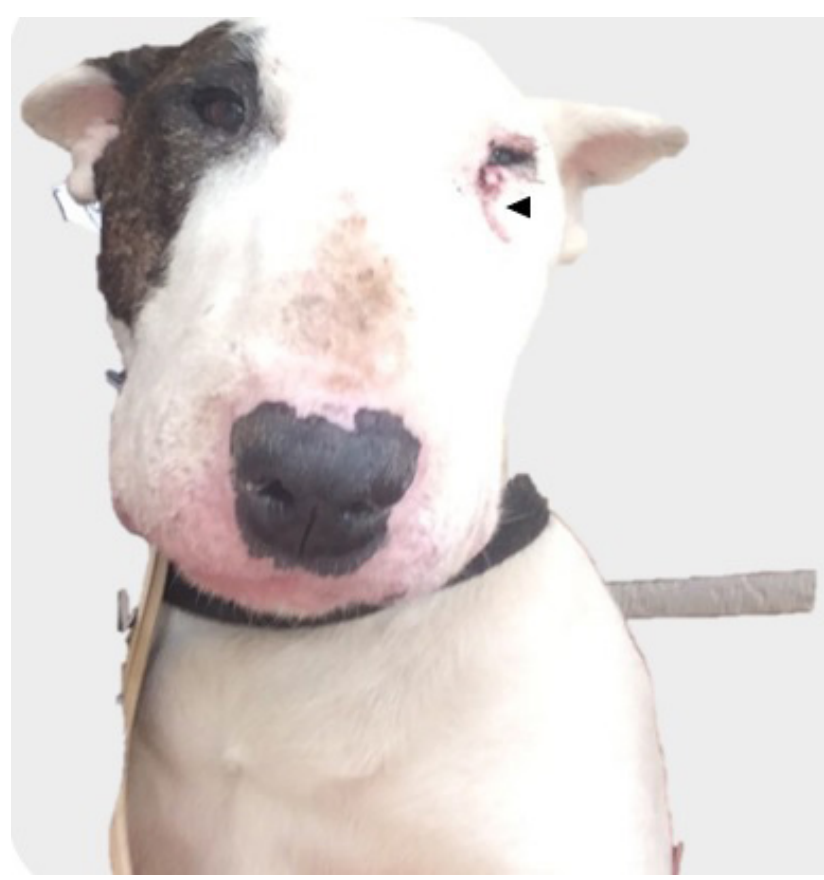

Figure 1. Picture of the animal reported, a 7-year-old canine, male, Bull Terrier, commited by a suspected squamous cell carcinoma near to the third eyelid (arrow). 
The first arterial blood pressure reading was obtained approximately $5 \mathrm{~min}$ after induction. At that time, hypotension was recognized (MAP $=45$ $\mathrm{mmHg}$ ), and a Lactated Ringer bolus (15 mL/kg, IV) was administered over $10 \mathrm{~min}$. Although the $\mathrm{ET}_{\text {ISO }}$ was $0.5 \%$ at that time, the dog did not show signs of light anesthesia (presence of palpebral reflexes and tachypnea/respiratory efforts with increased amplitude). Therefore, the $\mathrm{ET}_{\text {iso }}$ was decreased from 0.5 to $0.3 \%$ (oxygen flow rate $=1 \mathrm{~L} / \mathrm{min}$ ). Because MAP was still low (approximately $45 \mathrm{mmHg}$ ) after the fluid bolus was finished and the $\mathrm{ET}_{\text {ISO }}$ was decreased to $0.3 \%$, an IV bolus of ephedrine $(0.1 \mathrm{mg} / \mathrm{kg})$ was given without a noticeable improvement in MAP. A second ephedrine bolus (same dose) was given 5 min later but MAP was still $<50 \mathrm{mmHg}$.

A constant rate infusion (CRI) of dopamine was then initiated in an attempt to increase MAP to values $>60 \mathrm{mmHg}$. The dopamine CRI was set at $7.5 \mu \mathrm{g} / \mathrm{kg} / \mathrm{min}$ IV but MAP was further decreased to approximately $25 \mathrm{mmHg}$ and the CRI was increased to $10 \mu \mathrm{g} / \mathrm{kg} / \mathrm{min}$, IV, approximately $10 \mathrm{~min}$ after the initial CRI was set. This dopamine CRI was maintained for another 10 min without any improvement in MAP. At that time, 20 min after starting dopamine CRI, approximately 40-45 min after induction of anesthesia, it was decided to discontinue dopamine and isoflurane administration and the MRI procedure was aborted. Less than $5 \mathrm{~min}$ after zeroing the vaporizer, the animal raised its head and the orotracheal tube was removed. A $5 \mathrm{~mL} / \mathrm{kg}$, IV, bolus of $6 \%$ tetrastarch was administered over $5 \mathrm{~min}$, and MAP increased to approximately 60 to $70 \mathrm{mmHg}$ during the immediate period after the orotracheal tube was removed.

Chest radiographs, ECG and doppler echocardiography were recommended before planning a second anesthetic procedure. Both radiographs and ECG did not show remarkable abnormalities. The echocardiographic evaluation showed marginally decreased fractional shortening [23\%] (normal range for Bull Terriers: 24-41\%) [13]. Other parameters were within reference values.

\section{DISCUSSION}

The present report showed an ASA II dog with severe hypotensive crisis (MAP $<50 \mathrm{mmHg}$ ) during general anesthesia in which the procedure was aborted because hypotension was aggravated by dopamine.
Hypotension (MAP $<60 \mathrm{mmHg}$ ) is the most common complication in anesthetic practice and has been identified in $38 \%$ of canine patients undergoing general anesthesia for variety of procedures [15]. However, this anesthetic-related complication is usually responsive to standard therapeutic measures which include decreases in inhalant anesthetic concentrations, fluid administration, and use of inotropes/vasopressors in healthy animals (ASA I) or animals with mild systemic disease (ASA anesthetic risk I to II).

Although the dog of the present case report had a squamous cell tumour in the face, its ASA anesthetic risk was rated as II (mild systemic disease) because this illness showed no significant systemic repercussions when the animal was presented for anesthesia (normal appetite and behavior, absence of evidence of metastasis on X-ray evaluations, and biochemical markers of liver and kidney function within reference ranges).

Among the drugs used in the present case report, isoflurane is known for decreasing blood pressure in a dose-related manner because of its vasodilating properties [17]. It is evident that the dog reported here was highly sensitive to the hypotensive actions of isoflurane. The $\mathrm{ET}_{\text {ISO }}$ recorded when severe hypotension was first observed $(0.5 \%)$ at $5-10 \mathrm{~min}$ after orotracheal intubation represented only $40 \%$ of the minimum alveolar concentration of isoflurane (MAC) alone (1.28\%) [17]. In spite of the low $\mathrm{ET}_{\text {ISO }}$ at that time, the animal did not show signs of light anesthesia because the CNS depressing actions of isoflurane during the early phase of anesthesia were potentiated by premedication and induction drugs and, for this reason the $\mathrm{ET}_{\text {ISO }}$, was decreased to $0.3 \%$ but in an attempt to minimize hypotension.

Acepromazine is another drug that may have contributed to the hypotensive actions of isoflurane in the case reported here because it has also induces a vasodilatory effect [6]. Because acepromazine premedication may result in prolonged clinical effects, which may be related to its prolonged plasma half-life (7 h) [7], this drug might also have contributed to the lack of efficacy of ephedrine to treat hypotension in the present case report [16]. The increase in blood pressure mediated by ephedrine is related to increases in cardiac output $(\mathrm{CO})$ /myocardial contractility and to increases in systemic vascular resistance (SVR) [16,20]. The prolonged vasodilatory action of acepromazine might have contributed at least in part to the lack of efficacy 
of ephedrine for treating hypotension, although the dose of acepromazine used as premedication (0.01 $\mathrm{mg} / \mathrm{kg}$ ) was lower than the doses reported to interfere with the efficacy of vasopressor drugs ( 0.03 to 0.05 $\mathrm{mg} / \mathrm{kg})[12,16]$.

Acepromazine is best avoided in animals that already present or are at risk of developing hypotension. However, we decided to use a low dose $(0.01 \mathrm{mg} /$ $\mathrm{kg}$ ) as a part of the premedication regime because the animal showed an agitated but docile behavior, and his clinical condition did not indicate that he was prone to hypotension during anesthesia.

The aggravation in the hypotensive crisis (MAP decreased from 45-50 $\mathrm{mmHg}$ to approximately $25 \mathrm{mmHg}$ ) when dopamine was initiated to treat hypotension was unexpected. In isoflurane anesthetized dogs, dopamine CRIs ranging from 5 to $15 \mu \mathrm{g} / \mathrm{kg} / \mathrm{min}$ significantly increased $\mathrm{CO}$ but MAP was increased only with the highest infusion rate [12]. When acepromazine was used as premedication $(0.03 \mathrm{mg} / \mathrm{kg})$, dopamine's vasopressor effect recorded at $15 \mu \mathrm{g} / \mathrm{kg} / \mathrm{min}$, due to its increase in systemic vascular resistance with the highest dose, was partially blunted by the alfa-1 blocking properties of acepromazine.

Although acepromazine premedication may partially blunt dopamine's vasopressor action and reduce its efficacy to treat hypotension, this action alone does not explain the aggravation of the hypotension recorded in the present case report after dopamine was initiated. Paradoxical aggravation of hypotension during administration of vasopressor doses of dopamine could be related to the activation of the cardiopulmonary chemoreflex (CCR), previously known with the eponym Bezold-Jarisch reflex [1] (Figure 2). The CCR involves activation of mechano and baroreceptors in the heart [1] by inotropes such as dopamine and dobutamine [1]. Such activation originates vagal afferent impulses to the nucleus tractus solitarius of the central nervous system, which in turn originates parasympathetic afferent impulses to the heart [19] and reflex vasodilation [4]. The consequent increase in parasympathetic outflow, associated decreases in sympathetic activity [19], ultimately produces bradycardia and/ or hypotension $[14,18]$.

The CCR may has been reported in humans [14] and dogs $[8,18]$. In one case report, the use of dopamine to treat hypotension in 2 isoflurane anesthetized dogs was suspected to trigger the CCR [18]. Dopamine administration was associated with bradycardia (HR $\leq 50$ beats/min) in one animal at CRIs ranging from 7 to $15 \mu \mathrm{g} / \mathrm{kg} / \mathrm{min}$, while in the second animal the bradycardia observed during dopamine administration (7 $\mu \mathrm{g} / \mathrm{kg} / \mathrm{min}$ ) was also associated with an aggravation of hypotension (MAP $=40 \mathrm{mmHg}$ ) [18].

The paradoxical aggravation of hypotension during dopamine administration due to activation of the CCR reflex may be related to dopamine's vasodilatory effects (dopaminergic and beta adrenergic receptor stimulation) and an associated decrease in $\mathrm{CO}$ due to vagally mediated bradycardia. In CCR, the vasomotor inhibition occurs independently of cardiac modulation [2]. Therefore, bradycardia and hypotension could be isolated events [4]. In view of this mechanism, it could not be excluded that CCR activation may have caused the decrease of MAP after dopamine CRI in this dog.

\section{Bezold-Jarish Reflex}

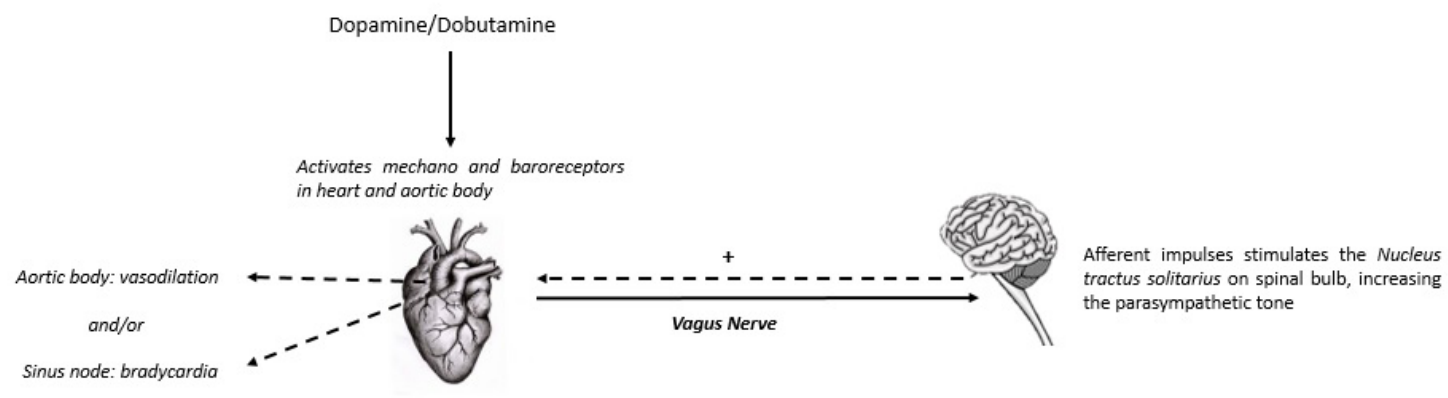

Figure 2. Schematic representation of Bezold-Jarish reflex. [Source: Elizabeth Regina Carvalho]. 
Dopamine acts as an agonist on alpha, beta-1, and beta- 2 receptors, in addition to its agonistic effects on dopaminergic receptors [5]. The affinity for these receptors, and consequently the hemodynamic effects are dose-related [3,5]. Until now, there are no studies investigating the pharmacokinetics of dopamine in dogs, and infusion rates are based in recommendations for humans [5]. Therefore, these infusion rates cannot be extrapolated to animals as absolutely values, but as intervals. At low infusion rates ( 1 to $3 \mu \mathrm{g} / \mathrm{kg} / \mathrm{min}$ ), as a general rule, dopaminergic effects prevails, leading to splanchnic and renal vasodilation, and inhibition of norepinephrine release [5]. At intermediate CRIs (5 to $8 \mu \mathrm{g} / \mathrm{kg} / \mathrm{min}$ ) dopamine has both beta- 1 and alpha- 1 adrenergic actions, and consequently positive inotropic effects with moderate vasoconstriction are seen [5]. At higher dopamine CRIs ( 8 to $20 \mu \mathrm{g} / \mathrm{kg} / \mathrm{min}$ ) the alpha adrenergic agonist action prevails, resulting peripheral vasoconstriction $[3,5,10]$.

However, it has been reported in humans [11], that dopamine plasma concentration can present marked inter-individual variation in spite of a fixed infusion rate. The large variability in plasma levels may result in marked differences in hemodynamic effects for a fixed infusion rate of dopamine, because different plasma levels can impact receptor affinity. Although the CRI used in this case report generally results in positive inotropic effect ( 7.5 to $10 \mu \mathrm{g} / \mathrm{kg} / \mathrm{min}$ ), it is possible that specifically in this dog, those rates were not high enough to promote this effect. The low ET co2 (20-25 $\mathrm{mmHg}$ ) with an identifiable expiratory plateau during anesthesia can be an evidence of low cardiac output [9] in this animal.

In conclusion, aggravation of the hypotensive crisis by dopamine in this case report could have been atribbuted to dopamine-induced vasodilation (dopaminergic effects) and to the failure of this drug in promoting beta- 1 and alfa- 1 adrenergic effects at the dose ranges used ( 7.5 to $10 \mu \mathrm{g} / \mathrm{kg} / \mathrm{min}$ ). Another possible explanation is the activation of the Bezold-Jarish reflex.

\section{MANUFACTURER}

${ }^{1}$ Bayer AG. Leverkusen, North Rhine-Westphalia, Germany.

Declaration of interest. The authors report no conflicts of interest. The authors alone are responsible for the content and writing of the paper.

\section{REFERENCES}

1 Aviado D.M. \& Guevara Aviado D. 2001. The Bezold-Jarisch reflex. A historical perspective of cardiopulmonary reflexes. Annals of the New York Academy of Sciences. 940(1961): 48-58.

2 Campagna J.A. \& Carter C. 2003. Clinical Relevance of the Bezold - Jarisch Reflex. Anesthesiology. (5): 1250-1260.

3 Corley K.T. 2004. Inotropes and vasopressors in adults and foals. Veterinary Clinics of North America: Equine Practice. 20(1): 77-106.

4 Erickson H.H. \& Detweiler D.K. 2006. Mecanismos de controle do sistema circulatório. In: Fisiologia Dos Animais Domésticos. 12.ed. Rio de Janeiro: Guanabara Koogan, pp.252-278.

5 Frishman W.H. \& Hotchkiss H. 1996. Selective and nonselective dopamine receptor agonists: an innovative approach to cardiovascular disease treatment. American Heart Journal. 132(4): 861-870.

6 Grasso S.C., Ko J.C., Weil A.B, Paranjape V. \& Constable P.D. 2015. Hemodynamic influence of acepromazine or dexmedetomidine premedication in isoflurane-anesthetized dogs. Journal of the American Veterinary Medical Association. 246(7): 754-764.

7 Hashem A., Kietzmann M. \& Scherkl R. 1992. The pharmacokinetics and bioavailability of acepromazine in the plasma of dogs. DTW. Deutsche Tierarztliche Wochenschrift. 99(10): 396-398.

8 Hofmeister E.H., Keenan K. \& Egger C.M. 2005. Dobutamine-induced bradycardia in a dog. Veterinary Anaesthesia and Analgesia. 32(2): 107-111.

9 Idris A.H., Staples E.D, O’Brien D.J., Melker R.J., Rush W.J., Del Duca K.D. \& Falk J.L. 1994. End-tidal carbon dioxide during extremely low cardiac output. Annals of Emergency Medicine. 23(3): 568-572.

10 Laste N.J. 2001. Cardiovascular pharmacotherapy: hemodynamic drugs and antiarrhythmic agents. The Veterinary Clinics of North America. Small Animal Practice. 31(6): 1231-1252.

11 MacGregor D.A., Smith T.E., Prielipp R.C, Butterworth J.F., James R.L. \& Scuderi P.E. 2000. Pharmacokinetics of dopamine in healthy male subjects. Anesthesiology. 92(2): 338-346.

12 Monteiro E.R., Teixeira Neto F.J., Castro V.B. \& Campagnol D. 2007. Effects of acepromazine on the cardiovascular actions of dopamine in anesthetized dogs. Veterinary Anaesthesia and Analgesia. 34(5): 312-321.

13O'Leary C.A., Mackay B.M., Taplin R.H. \& Atwell R.B. 2003. Echocardiographic parameters in 14 healthy English 
E.R. Carvalho, N.A. Garofalo, C.H. Girotto \& F.J. Teixeira Neto. 2018. Hypotension Aggravated by Dopamine in a Dog

Bull Terriers. Australian Veterinary Journal. 81(9): 535-542.

14 Rallidis L.S., Moyssakis I.E. \& Nihoyannopoulos P. 1998. Hypotensive response during dobutamine stress echocardiography in coronary patients: A common event of well-functioning left ventricle. Clinical Cardiology. 21(10): 747-752.

15 Redondo J.I., Rubio M., Soler G., Serra I., Soler C. \& Gómez-Villamandos R.J. 2007. Normal values and incidence of cardiorespiratory complications in dogs during general anaesthesia. A review of 1281 cases. Journal of Veterinary Medicine Series A: Physiology Pathology Clinical Medicine. 54(9): 470-477.

16Sinclair M.D. \& Dyson D.H. 2012. The impact of acepromazine on the efficacy of crystalloid, dextran or ephedrine treatment in hypotensive dogs under isoflurane anesthesia. Veterinary Anaesthesia and Analgesia. 39(6): 563-573.

17 Steffey E.P. \& Howland D. 1977. Isoflurane potency in the dog and cat. American Journal of Veterinary Research. 38(11): 1833-1836.

18 Tsompanidou P.P., Kazakos G.M. \& Anagnostou T.L. 2013. Dopamine-induced bradycardia in two dogs under isoflurane anaesthesia. Journal of Small Animal Practice. 54(12): 672-674.

19 Vasquez E.C., Meyrelles S.S., Mauad H. \& Cabral A.M. 1997. Neural reflex regulation of arterial pressure in pathophysiological conditions: Interplay among the baroreflex, the cardiopulmonary reflexes and the chemoreflex. Brazilian Journal of Medical and Biological Research. 30(4): 521-532.

20 Wagner A., Dunlop C. \& Chapman P. 1993. Effects of ephedrine on cardiovascular function and oxygen delivery in isoflurane-anesthetized dogs. American journal of veterinary research. 54(11): 1917-1922. 